\title{
Antimicrobial efficacy of commercially available dentifrices against newly isolated Streptococcus mutans
}

\author{
Md. Shahadat Hossaina , Nusrat Jahan Antora ${ }^{a}$ and Mohammad Shahnoor Hossain ${ }^{a *}$
}

\begin{abstract}
Background. The aim of the present study was to evaluate the anticariogenic activities of commercially available dentifrices such as, toothpastes and mouthwashes against the most prominent cariogenic bacteria $S$. mutans. Methods. Agar well diffusion method was employed to investigate the antibacterial activity against newly isolated clinical strains. Statistical analysis was performed using SPSS version 20 and one-way ANOVA and student t-test were used to compare the zone of inhibition. Results. We found that most of the commercially available dentifrices have antibacterial activity against $S$. mutans clinical isolates. We also found that fluoride and triclosan containing toothpaste has comparatively higher antibacterial effect than others. In addition, we observed that mouthwashes have relatively lower antibacterial activity than the toothpastes. Conclusions. In sum, our study indicated that sodium fluoride and triclosan containing toothpastes can be effectively used to maintain a good oral hygiene to prevent dental caries and other related diseases.
\end{abstract}

Keywords: Dentifrices, toothpaste, mouthwash, dental caries, antimicrobial activity, $S$. mutans.

Abbreviations: CFU, Colony forming unit; PCR, Polymerase Chain Reaction; ANOVA, Analysis of Variance; SPSS, Statistical Package for the Social Sciences.

Significance | Fluoride and triclosan containing dentifrices can be used to prevent oral infections.

*Correspondence: Mohammad Shahnoor Hossain, PhD, Assistant Professor, Department of Genetic Engineering \& Biotechnology, University of Dhaka, Dhaka-1000, Bangladesh. Phone: 880-2-9661900-7824; Fax: 880-2-9667222; Email: mshahnoor@du.ac.bd

Edited by Mohd. Raeed Jamiruddin, PhD, Brac University, Dhaka, Bangladesh. And accepted by the Editorial Board August 5, 2018 (received for review July 4, 2018)

\section{Introduction}

Dental caries along with other oral diseases such as gingivitis and periodontitis are the most common chronic disease prevalent in peoples of all walks of life and poses a grave public health concern world-wide (Dye, Li, \& Thorton-Evans, 2012); Khan, Jain, and Shrivastav (2008); (Ruff \& Niederman, 2018). Dental caries, also called tooth decay, is an infection caused by the breakdown of hard tissues of teeth by colonizing bacteria on the tooth surface (Caufield, Li, \& Dasanayake, 2005). Without any treatment, dental caries can lead to acute abscess, sepsis, systemic infection and death (Robertson \& Smith, 2009; Ruff \& Niederman, 2018). Streptococcus mutans is generally regarded as the principle causative agent of dental caries and is the most dominant bacteria in the dental plaque (Hossain \& Biswas, 2011). This pathogen is able to ferment carbohydrates and reduce the $\mathrm{pH}$ of the microenvironment which results in deminarelization of hard tissue of teeth (Struzycka, 2014).

Colonization and biofilm formation in the oral cavity can easily be prevented by using appropriate dentifrices and toothbrushes. The most common prevention mechanism to control dental caries involves regular use of dentifrices that may contain fluoride, triclosan, plant extracts, and surfactants to inhibit the growth of potential caries causing agent in addition to mechanical tooth-brushing (Buzalaf, Pessan, Honorio, \& ten Cate, 2011; Herlofson \& Barkvoll, 1996; Petersen, 2016; Walker, 1990). Fluoride is widely used as an active antimicrobial ingredient in dentifrices, which affect bacterial metabolism by acting as an enzyme inhibitor and facilitates remineralization of hard tissues of teeth (Marquis, 1995). It also acts to decrease the acid tolerance of bacteria and causes complete arrest of glycolysis of oral pathogen (Buzalaf et al., 2011). Triclosan is another non-ionic, broad spectrum antimicrobial agent which is commonly found in the formulation of different dentifrices (Prasanth, 2011). In higher

\section{Author Affiliation:}

a Department of Genetic Engineering \& Biotechnology, University of Dhaka, Dhaka-1000, Bangladesh

\section{Please cite this article:}

Hossain MS, Antora NJ, Hossain MS (2018). Antimicrobial efficacy of commercially available dentifrices against newly isolated Streptococcus mutans. Microbial Bioactives, $1(1), 029-032$ 
Table 1 | Ingredients of toothpastes and mouthwashes tested for antibacterial potential.

\begin{tabular}{|l|l|}
\hline Toothpaste & Ingredients \\
\hline $\mathbf{A}$ & $\begin{array}{l}\text { Sodium fluoride (0.24\%), calcium carbonate, water, } \\
\text { hydrated silica, sodium lauryl sulfate, cellulose gum, } \\
\text { sodium silicate, potassium nitrate, sodium saccharine }\end{array}$ \\
\hline $\mathbf{B}$ & $\begin{array}{l}\text { Sodium fluoride } 0.24 \% \text { +triclosan } 0.30 \% \\
\text { Sorbitol, hydrated Silica, sodium lauryl sulfate, cellulose } \\
\text { gum, zinc sulfate, sodium hydroxide, flavor, fluoride ion: } \\
1000 \mathrm{ppm}\end{array}$ \\
\hline $\mathbf{D}$ & $\begin{array}{l}\text { Meswak extract, non-fluoridated, calcium carbonate, } \\
\text { sorbitol, water, sodium saccharine, cellulose gum }\end{array}$ \\
\hline $\mathbf{E}$ & $\begin{array}{l}\text { Hydrated silica, sorbitol, glycerin, sodium monophosphate, } \\
\text { sodium chloride, sodium benzoate }\end{array}$ \\
\hline Mouthwash & $\begin{array}{l}\text { Triclosan, calcium carbonate, menthol, flavor, sodium } \\
\text { saccharin, di-calcium phosphate }\end{array}$ \\
\hline $\mathbf{F}$ & $\begin{array}{l}\text { Calcium carbonate, supari (Areca catechu), labanga } \\
\text { (Syzygium aromaticum), horitoki (Terminalia chebula) }\end{array}$ \\
\hline $\mathbf{G}$ & \begin{tabular}{l} 
Activated charcoal \\
\hline Activated \\
charcoal
\end{tabular} \\
\hline H & \\
\hline
\end{tabular}

Table 2 Antibacterial activity of toothpastes and mouthwashes against S. mutans. *SD indicates standard deviation.

\begin{tabular}{|l|l|l|}
\hline \multirow{2}{*}{ Toothpaste } & \multicolumn{2}{|l|}{$\begin{array}{l}\text { Zone of inhibition in diameter }(\mathrm{mm}) \\
(\mathbf{m e a n} \pm \text { SD })\end{array}$} \\
\cline { 2 - 3 } & $1.00 \mathrm{~g} / \mathrm{ml}$ & $100 \mathrm{mg} / \mathrm{ml}$ \\
\hline A & $23.7 \pm 1.8$ & $8.0 \pm 1.0$ \\
\hline B & $25.8 \pm 2.5$ & $8.0 \pm 1.0$ \\
\hline C & $20.8 \pm 2.1$ & $7.0 \pm 1.0$ \\
\hline D & $19.3 \pm 1.7$ & $6.0 \pm 0.5$ \\
\hline E & $16.8 \pm 2.0$ & $0.0 \pm 0.0$ \\
\hline F & $15.3 \pm 2.2$ & $0.0 \pm 0.0$ \\
\hline G & $13.7 \pm 2.0$ & $0.0 \pm 0.0$ \\
\hline H & $0.0 \pm 0.0$ & $0.0 \pm 0.0$ \\
\hline
\end{tabular}

concentrations, it directly kills bacteria by destabilizing membrane and in lower level, it inhibits bacterial growth by inactivating enzymes (R. M. Davies, Ellwood, \& Davies, 2004). In addition, triclosan inhibits the cyclooxygenase/ lipoxygenase pathways and has anti-inflammatory activities (R. Davies, Scully, \& Preston, 2010).

Toothpastes used for oral hygiene can be classified as drugs, but not cosmetics, because they contain active ingredients which are active against microorganisms (J Okpalugo J., 2009.). In spite of the continuous progress in the global oral health status, dental caries still remains as one of the formidable public health problem (Dye et al., 2012; Khan et al., 2008; Ruff \& Niederman, 2018). Although several studies have shed light on the antibacterial activities of different toothpastes against various oral pathogens, very little is known about their efficacy against clinical isolates. In an attempt to understand the efficacy of commonly used dentifrices, this study was designed to assess the anticariogenic activity of commercially available dentifrices against 30 clinical isolates of S. mutans.

\section{Material and methods}

\section{Microorganisms and culture conditions}

S. mutans strains were isolated from patients with dental caries, periodontitis and gingivitis using selective mitis-salivaries-bacitracin agar and identified by species-specific PCR as described previously (Rahman M., 2015.). 30 newly isolated S. mutans strains were used in this study and the strains were routinely cultivated in Todd Hewit medium (Sigma, USA) at $37^{\circ} \mathrm{C}$ for 24 $48 \mathrm{hrs}$ in microaerophilic condition.

\section{Antimicrobial activity of dentifrices}

To investigate the antimicrobial activity of dentifrices, five commercially available toothpastes, three known powdered mouthwashes, and one activated charcoal containing brand were purchased from the local market. The ingredients of these toothpaste and powdered mouthwashes are given in Table 1. Two different concentrations $(100 \mathrm{mg} / \mathrm{ml}$ and $1.0 \mathrm{~g} / \mathrm{ml})$ of dentifrices solution were prepared by mixing with distilled water.

Antibacterial activity of toothpastes and powdered mouthwashes was assessed by agar well diffusion method according to previously described method (Rahman M., 2015.). In sum, S. mutans strains were grown overnight and adjusted to 0.5 McFarland turbidity standards $\left(\sim 1.0 \times 10^{8} \mathrm{cfu} \mathrm{ml}^{-1}\right)$ and spread onto Todd Hewitt agar with a sterile cotton swab. Plates were then kept at room temperature for $15 \mathrm{~min}$ and wells were made using a sterile borer. The test dentifrices were then loaded into the well $(25 \mu \mathrm{l}$ in each well) and incubated overnight at $37^{\circ} \mathrm{C}$. Zone of inhibition, produced by antimicrobial activity of dentifrices was measured in diameter (mm) using a scale. $\mathrm{H}_{2} \mathrm{O}$ was used as negative control.

\section{Statistical Analysis}

For statistical analysis, SPSS version 20 was used. Comparisons between means of variables were performed using two sample $t$ tests and one way analysis of variance (ANOVA) with post hoc onferroni method.

\section{Results}

Antibacterial activity of various dentifrices. The composition of the different toothpastes and mouthwashes used in this study is shown in Table 1. Among the toothpastes and mouthwashes, brand $\mathrm{A}, \mathrm{B}$ and $\mathrm{C}$ contain fluoride, brand $\mathrm{B}$ and $\mathrm{F}$ contain triclosan and brand D contains meswak extract as antimicrobial ingredients. It was observed that brand B containing both sodium fluoride and triclosan has the highest antibacterial effect $(25.8$ $\mathrm{mm}$ ) against $S$. mutans followed by sodium fluoride containing brand A $(23.7 \mathrm{~mm})$ and brand $\mathrm{E}(16.8 \mathrm{~mm})$. Among the toothpastes, brand E, which doesn't contain triclosan or fluoride, has lowest inhibitory activity. Among the mouthwashes, triclosan containing brand $\mathrm{F}$ showed more inhibitory activity than other brands. However, the antibacterial activity was comparatively lower than that of toothpastes (Table 2). Mouthwash (brand G) supplemented with plant extract showed comparatively lower antimicrobial activity $(13.7 \mathrm{~mm}$ ) and activated charcoal (brand $\mathrm{H}$ ) showed no antimicrobial activity at all in our present assay conditions.

Although considerable level of antibacterial activity was observed 
Table 3 | Multiple comparison of different dentifrices.

\begin{tabular}{|l|l|l|}
\hline $\begin{array}{l}\text { Toothpaste } \\
\text { ID }\end{array}$ & $\begin{array}{l}\text { Similar activity } \\
\text { dentifrices }\end{array}$ & $\begin{array}{l}\text { Non-similar } \\
\text { activity dentifrices }\end{array}$ \\
\hline A & - & B, C, D, E, F, G, H \\
\hline B & - & A, C, D, E, F, G, H \\
\hline C & D & A, B, E, F, G, H \\
\hline D & C & A, B, E, F, G, H \\
\hline E & F & A, B, C, D, G, H \\
\hline F & E, G & A, B, C, D, H \\
\hline G & F & A, B, C, D, E, H \\
\hline H & - & A, B, C, D, E, F, G \\
\hline & & \\
\hline
\end{tabular}

Table 4 | Comparison the activity of two different groups.

\begin{tabular}{|l|l|l|l|}
\hline Group & Mean \pm sd & Mean \pm se & Significance \\
\hline Toothpaste & $21.29 \pm 3.796$ & $21.29 \pm 0.380$ & 0.000 \\
\hline Mouthwash & $14.50 \pm 2.253$ & $14.50 \pm 0.356$ & \\
\hline
\end{tabular}

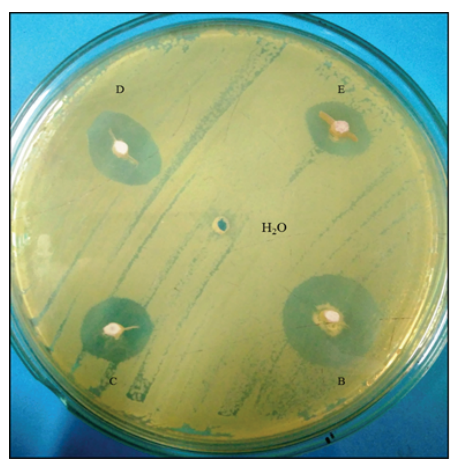

Figure 1 | Antimicrobial activity of toothpastes and powdered mouthwashes against isolated S. mutans. S. mutans strains were grown overnight and adjusted to 0.5 McFarland turbidity standards $\left(\sim 1.0 \times 10^{8}\right.$ colony forming units or $\left.\mathrm{cfu} \mathrm{m}^{-1}\right)$ and $100 \mu \mathrm{l}$ was seeded onto Todd Hewitt agar medium with a sterile cotton swab. After waiting for $\mathbf{3 0}$ min, wells were made using a sterile borer. The test dentifrices were then loaded into the well $(25 \mu \mathrm{l}$ in each well) and incubated overnight at $37^{\circ} \mathrm{C}$ under microaerophilic conditions. Zone of inhibition, produced by antimicrobial activity of dentifrices was measured in diameter $(\mathrm{mm})$ using a scale. $\mathrm{H}_{2} \mathrm{O}$ was used as negative control. B, C, D and E indicate toothpaste types. Each experiment was performed at least three times and representative plate is shown. against $S$. mutans strains, individual strains displayed different pattern of susceptibility to both toothpastes and mouthwashes (data not shown). We found that antibacterial activity of the tested dentifrices is concentration dependent and all of the bacterial strains were prominently inhibited when we used high concentration of dentifrices.

Multiple comparisons of different dentifrices: Multiple comparisons among different dentifrices with $1.00 \mathrm{~g} / \mathrm{ml}$ concentration were performed to determine the comparative toothpaste activity using statistical program, SPSS version 20 by applying one way ANOVA with post hoc Bonferroni method. The result of the statistical analysis with significance level $\alpha=0.05$ is showed in Table 3. Comparison of the antibacterial potential between toothpastes and mouthwash groups against caries causing $S$. mutans using statistical analysis program, SPSS version 20 indicated that commercial toothpastes have relatively higher level of antibacterial activity in compare to mouthwashes (Table 4).

\section{Discussion}

Oral health is the indicator of overall health status of a person and poor oral health acts as a risk factor for numerous other diseases such as heart attack, atherosclerosis, coronary heart diseases, rheumatoid arthritis and cancer (Kampoo, Teanpaisan, Ledder, \& McBain, 2014; Lim, Totsika, Morrison, \& Punyadeera, 2017; Loyola-Rodriguez, Martinez-Martinez, Abud-Mendoza, Patino-Marin, \& Seymour, 2010) . Human oral cavity, which contains more than 700 different bacterial species, needs to maintain a delicate balance to ensure a good oral hygiene (Kilian et al., 2016). The best way to control oral diseases is to maintain regular oral hygiene by toothbrushing with dentifrices. Microorganism residing in our oral cavity forms biofilm, promotes imbalance of oral environment and accounts for most of the dental and other systemic diseases. Therefore, it is essential to use dentifrices containing antimicrobial agent regularly to maintain a good oral health.

In this study, we investigated the antimicrobial activity of five different toothpastes, two different powdered mouthwashes and one activated charcoal containing different chemical ingredients against the most cariogenic bacteria, S. mutans isolated from patients with oral diseases. Toothpaste brand B, which contains triclosan and sodium fluoride as their main ingredients, exhibited the most prominent antimicrobial activity and activated charcoal showed no antimicrobial activity at all (Figure 1 and Table 2). Multiple analysis of comparative antimicrobial activity of dentifrices demonstrated that toothpaste brand $\mathrm{C}$ and $\mathrm{D}$ has similar antibacterial activity although they contain fluoride and meswak extract as antimicrobial ingredient respectively. Toothpaste brand E exhibited relatively lower antimicrobial activity in compare to other dentifrices. The apparent less antimicrobial activity can be attributed to the absence of active ingredients such as triclosan and fluoride. When we analyzed the toothpaste and mouthwash groups with student $t$-test, we found that toothpastes have significantly higher antimicrobial activity than powdered mouthwashes (Table 4). In accordance with several previous reports, our results suggest that dentifrices containing triclosan and fluoride are more effective than non-triclosan and non-fluoride dentifrices (Fine et al., 2006; Inetianbor JE., 2014; J Okpalugo J., 2009.; Marinho, Higgins, Sheiham, \& Logan, 2003). Our results are in agreement with Barnett's report which showed the antibacterial activity of 
different mouthwashes (Barnett, 2006).

Dentifrices used in vivo condition, generally gets diluted by saliva. As a result, it is possible that antimicrobial compounds will be buffered in saliva at varying concentrations. Therefore, it is not always true that dentifrices producing the largest zone of inhibition contain highest antimicrobial ingredients. Moreover, different dentifrices contain different antimicrobial ingredients that may diffuse at varying rates. Hence, in vitro test result can't exactly pinpoint the antimicrobial efficacy of toothpastes and mouthwashes in vivo conditions. Differential pattern of antibacterial activities of various toothpastes and mouthwashes can be attributed to variations in formulations, active components and their interactions with other ingredients.

\section{Conclusions}

In sum, this study has shown that most of the commonly found toothpastes and mouthwashes available in Bangladesh have prominent antibacterial activity against the clinical isolates of $S$. mutans. It was found that dentifrices containing triclosan and fluoride are most effective against this oral pathogen. Therefore, dentifrices containing fluoride and triclosan can be effectively used to maintain a good oral hygiene in daily basis.

\section{Acknowledgement}

We thank University Grant Commission, Bangladesh for providing the grant to conduct this project.

\section{Competing financial interests}

The authors declare that they have no conflict of interest.

\section{Author contributions}

$\mathrm{MSH}^{*}$ : Conceived and designed the experiments, made critical revisions, and edited and approved final version. $\mathrm{MSH}^{1}$ and $\mathrm{NJA}^{2}$ : Performed the experiments. MSH: Wrote the initial manuscript and analyzed data.

\section{References}

Barnett, M. L. (2006). The oral-systemic disease connection. An update for the practicing dentist. J Am Dent Assoc, 137 Suppl, 5S-6S.

Buzalaf, M. A., Pessan, J. P., Honorio, H. M., \& ten Cate, J. M. (2011). Mechanisms of action of fluoride for caries control. Monogr Oral Sci, 22, 97-114. doi:10.1159/000325151

Caufield, P. W., Li, Y., \& Dasanayake, A. (2005). Dental caries: an infectious and transmissible disease. Compend Contin Educ Dent, 26 (5 Suppl 1), 10-16.

Davies, R., Scully, C., \& Preston, A. J. (2010). Dentifrices--an update. Med Oral Patol Oral Cir Bucal, 15(6), e976-982.

Davies, R. M., Ellwood, R. P., \& Davies, G. M. (2004). The effectiveness of a toothpaste containing triclosan and polyvinyl-methyl ether maleic acid copolymer in improving plaque control and gingival health: a systematic review. J Clin Periodontol, 31(12), 1029-1033. doi:10.1111/j.1600-051X.2004.00614.x

Dye, B. A., Li, X., \& Thorton-Evans, G. (2012). Oral health disparities as determined by selected healthy people 2020 oral health objectives for the United States, 2009-2010.
NCHS Data Brief(104), 1-8

Fine, D. H., Furgang, D., Markowitz, K., Sreenivasan, P. K., Klimpel, K., \& De Vizio, W. (2006). The antimicrobial effect of a triclosan/copolymer dentifrice on oral microorganisms in vivo. J Am Dent Assoc, 137(10), 1406-1413.

Herlofson, B. B., \& Barkvoll, P. (1996). Oral mucosal desquamation caused by two toothpaste detergents in an experimental model. Eur J Oral Sci, 104(1), 21-26.

Hossain, M. S., \& Biswas, I. (2011). Mutacins from Streptococcus mutans UA159 are active against multiple streptococcal species. Appl Environ Microbiol, 77(7), 2428-2434. doi:10.1128/AEM.02320-10

Inetianbor JE., E. G., Yakubu JM. and Ogodo AC. (2014). In-vitro antibacterial activity of commonly used toothpastes in nigeria against dental pathogens. J Adv Sci Res., 5(2)(40-45) J Okpalugo J., I. K., Inyang US. . (2009.). Toothpaste formulation efficacy in reducing oral flora. Tropical Journal of Pharmaceutical Research, 8 (1), 71-77.

Kampoo, K., Teanpaisan, R., Ledder, R. G., \& McBain, A. J. (2014). Oral bacterial communities in individuals with type 2 diabetes who live in southern Thailand. Appl Environ Microbiol, 80(2), 662-671. doi:10.1128/AEM.02821-13

Khan, A. A., Jain, S. K., \& Shrivastav, A. (2008). Prevalence of Dental Caries among the Population of Gwalior (India) in Relation of Different Associated Factors. Eur J Dent, 2(2), 81-85.

Kilian, M., Chapple, I. L., Hannig, M., Marsh, P. D., Meuric, V., Pedersen, A. M., .. Zaura, E. (2016). The oral microbiome - an update for oral healthcare professionals. Br Dent J, 221(10), 657-666. doi:10.1038/sj.bdj.2016.865

Lim, Y., Totsika, M., Morrison, M., \& Punyadeera, C. (2017). Oral Microbiome: A New Biomarker Reservoir for Oral and Oropharyngeal Cancers. Theranostics, 7(17), 4313-4321. doi: 10.7150/thno.21804

Loyola-Rodriguez, J. P., Martinez-Martinez, R. E., Abud-Mendoza, C., Patino-Marin, N., \& Seymour, G. J. (2010). Rheumatoid arthritis and the role of oral bacteria. J Oral Microbiol, 2. doi:10.3402/jom.v2i0.5784

Marinho, V. C., Higgins, J. P., Sheiham, A., \& Logan, S. (2003). Fluoride toothpastes for preventing dental caries in children and adolescents. Cochrane Database Syst $\operatorname{Rev}(1)$, CD002278. doi:10.1002/14651858.CD002278

Marquis, R. E. (1995). Antimicrobial actions of fluoride for oral bacteria. Can J Microbiol, 41(11), 955-964.

Petersen, R. C. (2016). Triclosan antimicrobial polymers. AIMS Mol Sci, 3(1), 88-103. doi:10.3934/molsci.2016.1.88

Prasanth, M. (2011). Antimicrobial efficacy of different toothpastes and mouthrinses: an in vitro study. Dent Res J (Isfahan), 8(2), 85-94.

Rahman M., I. M., Islam MN., Hossain MS. (2015.). Isolation and Identification of Oral Bacteria and Characterization for Bacteriocin Production and Antimicrobial Sensitivity. Dhaka Univ. J. Pharm. Sci., 14((1)), 103-109.

Robertson, D., \& Smith, A. J. (2009). The microbiology of the acute dental abscess. J Med Microbiol, 58(Pt 2), 155-162. doi:10.1099/jmm.0.003517-0

Ruff, R. R., \& Niederman, R. (2018). Comparative effectiveness of treatments to prevent dental caries given to rural children in school-based settings: protocol for a cluster randomised controlled trial. BMJ Open, 8(4), e022646. doi:10.1136/bmjopen-2018-022646 Struzycka, I. (2014). The oral microbiome in dental caries. Pol J Microbiol, 63(2), 127-135. Walker, C. (1990). Effects of sanguinarine and Sanguinaria extract on the microbiota 